\title{
Helicobacter pylori eradication for low-grade gastric mucosa- associated lymphoid tissue lymphoma is more successful in inducing remission in distal compared to proximal disease
}

\author{
JS Kim ',4, SJ Chung ${ }^{1,4}$, YS Choi', JH Cheon², CW Kim³, SG Kim', HC Jung' and IS Song,,I \\ 'Department of Internal Medicine, Liver Research Institute, Seoul National University College of Medicine, Seoul, Korea; ${ }^{2}$ Department of Internal \\ Medicine, Yonsei University College of Medicine, Seoul, Korea; ${ }^{3}$ Department of Pathology, Seoul National University College of Medicine, Seoul, Korea
}

A series of studies has shown that Helicobacter pylori eradication induces remission in most patients with low-grade gastric mucosaassociated lymphoid tissue (MALT) lymphoma. However, there have been few reports about the effect of bacterial treatment on the gastric MALT lymphoma in Korea, a well-known $\mathrm{H}$. pylori endemic area. A total of I I I H. pylori-infected patients were prospectively enrolled in Seoul National University Hospital and 99 among them were completely followed up according to our protocol. After $H$. pylori eradication, tumoural response was evaluated by endoscopy and histopathology every $2-3$ months till complete remission (CR) and every 6 months after achieving CR. Median follow-up period was 4 I months (range, I I- 125 months). Helicobacter pylori was successfully eradicated in all 99 patients and CR was obtained in 84 (84.8\%) of 99 patients. The median time to reach CR was 3 months and $94 \%$ of $C R$ is in continuous complete remission. Five patients with CR relapsed after 10-22 months without the evidence of $\mathrm{H}$. pylori reinfection. Cumulative recurrence rate was $2.3,7.7$ and $9.3 \%$ at I, 2 and 3 years, respectively. Tumours were mainly located in distal stomach (67.7\%) and tumours in distal stomach were associated with more favourable response than those in proximal stomach $(P=0.00 \mathrm{I})$. Majority of patients with low-grade gastric MALT lymphoma treated by exclusive $\mathrm{H}$. pylori eradication have a favourable long-term outcome, offering a real chance of cure. Tumour location could be a predictive factor for remission following $H$. pylori eradication.

British Journal of Cancer (2007) 96, I 324- 1328. doi: 10. I038/sj.bjc.6603708 www.bjcancer.com

Published online 3 April 2007

(c) 2007 Cancer Research UK

Keywords: mucosa-associated lymphoid tissue lymphoma; Helicobacter pylori; long-term outcome; tumour location

Recently, Helicobacter pylori eradication is considered wellaccepted initial therapy in cases of localised (stage I) low-grade gastric mucosa-associated lymphoid tissue (MALT) lymphoma, in which recently published series confirmed $62-95 \%$ complete remission (CR) rate (Neubauer et al, 1997; Savio et al, 2000; Montalban et al, 2001; Fischbach et al, 2004; Wundisch et al, 2005). The variation of $\mathrm{CR}$ rates may be due to the heterogeneity of previous studies, particularly as regards of study design and clinical characteristics. Data in some articles are lacking regarding $H$. pylori infection status and/or tumour extension and stage. Our study addressed these issues by strict study design, which comprised precise inclusion criteria, complete tumour staging and meticulous endoscopic follow-up.

In stage-I cases, the depth of invasion seems to be a predictive factor because previous studies have shown the evidence that

\footnotetext{
*Correspondence: Dr IS Song, Department of Internal Medicine, Seoul National University College of Medicine, 28 Yongon-Dong, Chongno-Gu, Seoul II 0-744, South Korea;

E-mail: issong@snu.ac.kr

${ }^{4}$ These two authors have contributed equally to this work.

Received II January 2007; revised 28 February 2007; accepted 28 February 2007; published online 3 April 2007
}

tumours that invade muscularis propria or beyond are more likely not to respond to eradication therapy than those restricted to submucosa (Sackmann et al, 1997; Steinbach et al, 1999; RuskoneFourmestraux et al, 2001). However, clinical determination of the depth of invasion is not perfect without the evaluation of a surgical specimen. Therefore, there remains a need for alternative prognostic markers for stage-I gastric MALT lymphomas at diagnosis. The aim of this large prospective single-centre study was to determine the long-term outcome of exclusive $H$. pylori eradication therapy on low-grade stage-I gastric MALT lymphoma and to define the predictive factors of clinical response.

\section{PATIENTS AND METHODS}

\section{Patients and diagnostic criteria}

From January 1996 to December 2006, consecutive patients with H. pylori-positive stage-I (Lugano classification) (Rohatiner et al, 1994) low-grade gastric MALT lymphoma were prospectively enrolled in single centre (Seoul National University Hospital). The diagnosis of low-grade gastric MALT lymphoma was made according to the criteria of Isaacson and the recently published World Health Organization (WHO) classification of lymphoid 
neoplasms for extranodal marginal zone B-cell lymphoma of MALT type.

\section{Initial stage work-up and $H$. pylori eradication therapy}

Complete staging work-up (de Jong et al, 1999; Raderer et al, 2000) consisted of the detailed physical examination, chest X-ray, abdomen CT, endoscopic ultrasonography (EUS) and bilateral bone marrow examination. Due to a lack of availability in early period, EUS could not be performed in 28 cases.

H. pylori infection status was determined by histologic examination and rapid urease test $\left(\mathrm{CLO}^{\mathrm{TM}}\right.$, Delta West, Bentley, Western Australia). Helicobacter pylori status was considered to be positive if any of the two tests was positive. Only patients with H. pylori-positive and stage-I gastric MALT lymphoma were enrolled in the study. All patients were assigned to the 7-day course of omeprazole ( $20 \mathrm{mg}$ b.i.d.), amoxicillin (1000 mg b.i.d.) and clarithromycin (500 mg b.i.d.). Second-line therapy consisted of a quadruple regimen containing omeprazole $20 \mathrm{mg}$ b.i.d., tripotassium dicitrate bismuthate $300 \mathrm{mg}$ q.i.d., metronidazole $500 \mathrm{mg}$ t.i.d. and tetracycline $500 \mathrm{mg}$ q.i.d. for 7 days.

\section{Remission evaluation following $H$. pylori eradication}

Response was assessed according to the WHO criteria: CR was defined as no macroscopic tumour, histologically confirmed; a partial response when at least $50 \%$ tumour reduction was found; stable disease in case of variation within either $50 \%$ decrease of $25 \%$ increase; and progressive disease when an increase of at least $25 \%$ was present (Wotherspoon et al, 1993). Treatment was considered to have failed if patients showed no improvement or did not meet criteria for CR within 1 year after $H$. pylori eradication.

Patients first underwent follow-up endoscopy at 4-8 weeks after the completion of antibiotic therapy for the evaluation of $H$. pylori eradication. For determination of the clinical response, endoscopy with multiple biopsies from tumours and suspicious areas was performed at 2-3 months after the confirmation of eradication. Then follow-up endoscopy was repeated every 2-3 months until $\mathrm{CR}$ was achieved or until treatment failure for 1 year. In cases with $\mathrm{CR}$, endoscopic examination and biopsy were performed every 6 months and the median number of endoscopies the patients in CR was nine. At each follow-up endoscopic examination, two separate biopsies from macroscopically normal mucosa of the antrum and body were evaluated for $H$. pylori infection. In cases of treatment failure to $H$. pylori eradication, patients were referred for surgery or radiation therapy (Figure 1).

\section{Statistical analysis}

Data are expressed as median with range. In between-group comparisons, continuous variables were analysed by the Student's $t$-test and categorical variables using the $\chi^{2}$-test or Fisher's exact test. The Kaplan-Meier method was used to estimate remission duration. Analyses were performed using the Statistical Package for the Social Sciences (version 12.0; SPSS INC. Chicago, IL, USA). All statistical tests were two-sided, and a value of $P<0.05$ was considered to be statistically significant.

\section{RESULTS}

\section{Clinicopathologic and endoscopic characteristics}

A total of 111 patients were enrolled initially and 12 patients did not complete our protocol. Finally, 99 of the patients (M:F, 41:58; age median 52 years (24-77 years)) were evaluated in this study. There were fewer male than female patients and the male to female ratio was $1: 1.4$
The macroscopic tumour type was determined according to the classification of Watanabe with minor modifications, as follows (Watanabe, 1980): (i) protruding, mass-like (9.1\%); (ii) granular, gastritis-like (19.2\%); (iii) depressed, erosion (50.5\%); (iv) excavated, ulceration (15.2\%); and (v) mixed (6.1\%). The neoplasm was located in the distal stomach (antrum, angle and low body) in $67.7 \%$. The depth of lymphoma involvement in the gastric wall was determined by EUS in 67 patients and by histologic examination of surgically resected specimen in 14 patients; most of the cases confined to the musoca $(55.6 \%)$ or submucosa $(34.6 \%)$ (Table 1$)$.

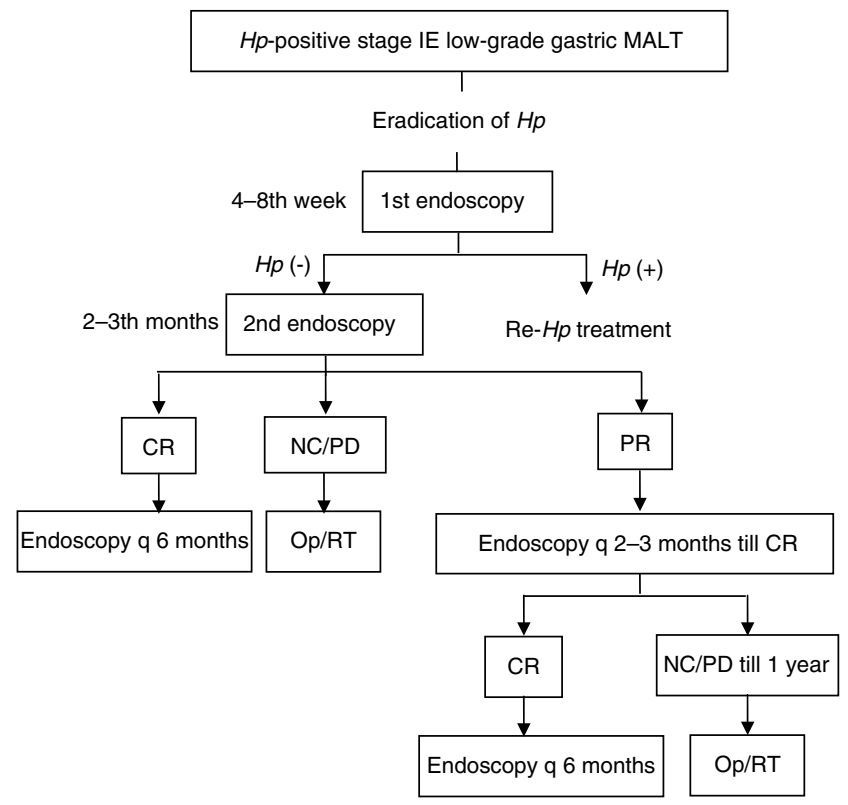

Figure I Schematic study design for the treatment approach and followup of patients with $H$. pylori-positive early-stage low-grade gastric MALT lymphoma. $H p=$ Helicobacter pylori; MALT = mucosa-associated lymphoid tissue; $C R=$ complete remission; $N C=$ no change; $P R=$ partial response; $\mathrm{O} p=$ operation; $\mathrm{R} T=$ radiation therapy.

Table I Clinical and endoscopic characteristics $(n=99)$

\begin{tabular}{lcr}
\hline Clinicopathologic characteristics & No. of patients & $\%$ \\
\hline Age, median (range), years & $52(24-77)$ & \\
Sex (male:female) & $41: 58$ & \\
& & \\
Endoscopic appearance & 9 & 9.1 \\
I: protruding, mass & 19 & 19.2 \\
II: granular, gastritis & 50 & 50.5 \\
III: depressed, erosion & 15 & 15.2 \\
IV: excavated, ulceration & 6 & 6.1 \\
V: mixed & & \\
& 29 & 29.3 \\
Endoscopic location & 67 & 67.7 \\
Proximala & 3.0 \\
Distal & & \\
Multifocal & & \\
Depth of gastric wall involvement & & \\
Mucosa & $45 / 81$ & 55.6 \\
Submucosa & $28 / 81$ & 34.6 \\
Muscularis propria or beyond & $8 / 81$ & 9.9 \\
\hline
\end{tabular}

a Mid body, high body, fundus or cardia. ${ }^{b}$ Antrum, angle or low body. ${ }^{\mathrm{C}}$ Evaluated by EUS in 67 patients and by histologic examination of surgical specimen in 14 patients. 


\section{H. pylori eradication and tumoural response}

Cure of $H$. pylori infection was documented in all patients (99 out of 99); eight patients needed a second-line treatment for successful eradication.

Median follow-up period was 41 months (11-125 months). Long-term outcome was characterised by CR of lymphoma in 84 out of 99 cases $(84.8 \%)$. The median time to get CR after the completion of antibiotic therapy in $H$. pylori-eradicated patients was 3 months (1-20 months).

Table 2 shows the probabilities of CR stratified by clinicopathologic factors. The depth of tumour invasion determined by EUS or surgery strongly correlated with the outcome of eradication therapy. Complete remission was observed in 62 out of 73 $(84.9 \%)$ patients with tumours that were limited to the mucosa or submucosa, but only in four out of eight (50.0\%) patients with tumours that had invaded the muscularis propria or beyond $(P=0.031)$. Interestingly, in our analysis, anatomic location in the stomach also influenced the tumour response. Patients with distal tumours had a higher CR rate $(92.5 \%)$ than patients with proximal tumours $(65.5 \%)(P=0.001)$. We analysed other clinical characteristics (age, sex, performance status, levels of haemoglobin, $\mathrm{LDH}$ and $\beta 2$-microglobulin at diagnosis) that showed no statistically significant associations with the clinical response.

Fifteen patients (15.2\%) showed persistent disease at 12 months after the eradication therapy. They underwent operation or radiation therapy and had $\mathrm{CR}$ in the subsequent follow-up (Figure 2).

\section{Recurrence of MALT lymphoma and reinfection of $H$. pylori during follow-up}

During median follow-up of 41 months, five patients (6.0\%) relapsed with a low-grade lymphoma at 10-22 months after the remission without the evidence of reinfection; they were referred for alternative treatment (operation or radiotherapy) (Figure 2). Endoscopic appearances, location, depth of invasion and H. pylori status were not associated with recurrence (Table 3). Cumulative recurrence rate by Kaplan-Meyer survival analysis was 2.3, 7.7 and $9.3 \%$ at 1,2 and 3 years after CR, respectively (Figure 3 ).

H. pylori has reinfected in 11 out of 99 patients (11.1\%). But there was no evidence of disease relapse and $H$. pylori was eradicated in all of them.

Table 2 Risk factor analysis for non-response of MALT lymphoma

\begin{tabular}{|c|c|c|c|}
\hline Characteristics & $\begin{array}{c}\text { Non-response } \\
(n=15)\end{array}$ & $\begin{array}{c}\text { Response } \\
(n=84)\end{array}$ & $P$-value \\
\hline Endoscopic appearance (\%) & & & NS \\
\hline I: protruding, mass & $3(20.0)$ & $6(7.1)$ & \\
\hline Il: granular, gastritis & I (6.7) & $18(21.4)$ & \\
\hline III: depressed, erosion & $6(40.0)$ & $44(52.4)$ & \\
\hline IV: excavated, ulceration & $4(26.7)$ & $11(13.1)$ & \\
\hline V: mixed & I $(6.7)$ & $5(6.0)$ & \\
\hline Endoscopic location (\%) & & & 0.001 \\
\hline Proximal $^{\mathrm{a}}$ & $10(80.0)$ & $19(22.6)$ & \\
\hline Distal $^{b}$ & $5(20.0)$ & $62(73.8)$ & \\
\hline Multifocal & $0(0)$ & $3(3.6)$ & \\
\hline \multicolumn{4}{|l|}{ Depth of gastric wall involvement ${ }^{c}(\%)$} \\
\hline Mucosa & 5/15 (33.3) & $40 / 66(60.6)$ & \\
\hline Submucosa & $6 / 15(40.0)$ & $22 / 66(33.3)$ & 0.064 \\
\hline Muscularis propria or beyond & $4 / 15(26.7)$ & $4 / 66(6.0)$ & 0.031 \\
\hline
\end{tabular}

MALT = mucosa-associated lymphoid tissue. ${ }^{a}$ Mid body, high body, fundus or cardia. ${ }^{b}$ Antrum, angle or low body. 'Evaluated by EUS in 67 patients and by histologic examination of surgical specimen in 14 patients.

\section{DISCUSSION}

Our study showed predominant distal stomach location of gastric MALT lymphoma (67.7\%). Although MALT lymphomas can occur in any region of the stomach, they located most commonly in the antrum and low body (Isaacson, 1996; Kim et al, 2001; Paik et al, 2002; Kahl, 2003), which reflects localisation of the highest concentrations in colonised individuals of $H$. pylori organisms and acquired lymphoid tissue (Wotherspoon, 1998). Interestingly, in our analysis, the patients with treatment failure showed a significantly greater frequency of proximal tumour location $(P=0.001)$. Our possible explanation is that the pathophysiology of proximal MALT lymphoma differs from that of distal lymphoma; proximal lymphoma might also be associated with H. pylori infection or may be $H$. pylori-independent autoimmune gastritis, which is generally proximal in distribution (Dixon et al, 1996). Recent studies indicate that autoimmune gastritis may derive from $H$. pylori infection and suggest that antibiotic resistant

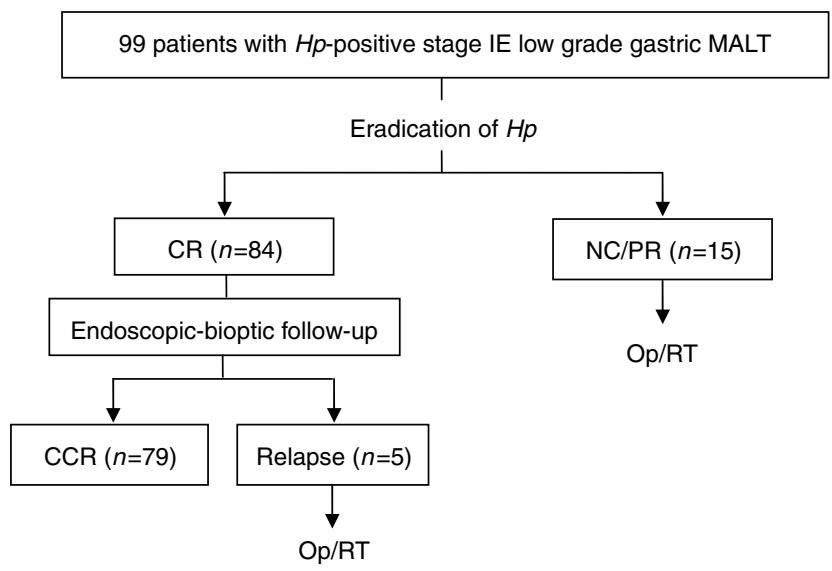

Figure 2 Clinical response and follow-up of the 99 patients on the basis of macroscopic and histologic findings. $H p=$ Helicobacter pylori; $M A L T=$ mucosa-associated lymphoid tissue; $C R=$ complete remission; $\mathrm{NC}=$ no change; $\mathrm{PR}=$ partial response; $\mathrm{CCR}=$ continuous complete remission.

Table 3 Risk factor analysis for recurrence of MALT lymphoma

\begin{tabular}{|c|c|c|c|}
\hline Characteristics & $\begin{array}{l}\text { Recurrence } \\
\quad(n=5)\end{array}$ & $\begin{array}{l}\text { No recurrence } \\
\quad(n=79)\end{array}$ & $P$-value \\
\hline \multicolumn{3}{|l|}{ Endoscopic appearance (\%) } & NS \\
\hline I: protruding, mass & $0(0)$ & $6(7.6)$ & \\
\hline II: granular, gastritis & $0(0)$ & $18(22.8)$ & \\
\hline III: depressed, erosion & $4(80.0)$ & $40(50.6)$ & \\
\hline IV: excavated, ulceration & I (20.0) & $10(12.7)$ & \\
\hline $\mathrm{V}:$ mixed & $0(0)$ & $5(6.3)$ & \\
\hline \multicolumn{3}{|l|}{ Endoscopic location (\%) } & NS \\
\hline Proximal $^{\mathrm{a}}$ & $2(40.0)$ & $16(20.3 \%)$ & \\
\hline Distal $^{\mathrm{b}}$ & $3(60.0)$ & $60(75.9 \%)$ & \\
\hline Multifocal & $0(0)$ & $3(3.8 \%)$ & \\
\hline \multicolumn{3}{|c|}{ Depth of gastric wall involvement ${ }^{c}(\%)$} & NS \\
\hline Mucosa & $3 / 5(60.0)$ & $45 / 75(60.0)$ & \\
\hline Submucosa & $2 / 5(40.0)$ & $25 / 75(33.3)$ & \\
\hline Muscularis propria or beyond & $0(0)$ & $5 / 75(6.7)$ & \\
\hline Median time to CR (months) & 3 & 3 & NS \\
\hline H. pylori reinfection (\%) & $0(0)$ & || (13.9) & NS \\
\hline
\end{tabular}

MALT = mucosa-associated lymphoid tissue. ${ }^{a}$ Mid body, high body, fundus or cardia. ${ }^{b}$ Antrum, angle or low body. 'Evaluated by EUS in 66 patients and by histologic examination of surgical specimen in 14 patients. 


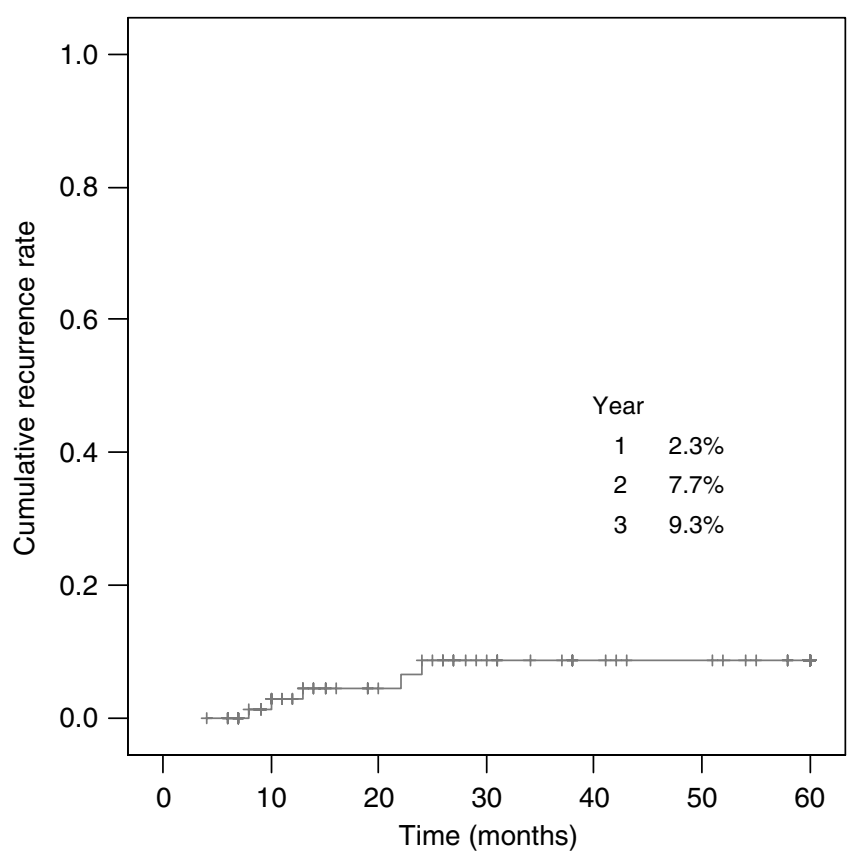

Figure 3 Recurrence of MALT lymphoma during a median 4I months follow-up period. Cumulative recurrence rate was plotted with Kaplan-Meyer survival analysis.

tumours may be sustained by autoantigen-responsive $\mathrm{T}$ cells (Negrini et al, 1991; Greiner et al, 1994). Hence, the subset of $H$. pylori-eradicated MALT lymphomas in proximal stomach might be associated with autoimmune-related or autonomous tumours in patients with previous $H$. pylori gastritis, which do not respond to H. pylori eradiation (Steinbach et al, 1999; Ruskone-Fourmestraux et al, 2001). Our unpublished data for 27 patients with $H$. pylorinegative gastric MALT lymphoma revealed the predominant proximal location of lymphomas (62.9\%), which suggests an important role of $H$. pylori-independent pathogenesis in case of proximal MALT lymphoma.

Although two large-scale German groups have shown the long-term outcome of gastric MALT lymphoma after $H$. pylori eradication (Fischbach et al, 2004; Wundisch et al, 2005), reports about predictive factors for clinical response after eradication therapy are rare. Our results might be valuable on the

\section{REFERENCES}

De Jong D, Aleman BM, Taal BG, Boot H (1999) Controversies and consensus in the diagnosis, work-up and treatment of gastric lymphoma: an international survey. Ann Oncol 10: 275-280

Dixon MF, Genta RM, Yardley JH, Correa P (1996) Classification and grading of gastritis. The updated Sydney System. International Workshop on the Histopathology of Gastritis, Houston 1994. Am J Surg Pathol 20: $1161-1181$

Fischbach W, Goebeler-Kolve ME, Dragosics B, Greiner A, Stolte M (2004) Long-term outcome of patients with gastric marginal zone B-cell lymphoma of mucosa-associated lymphoid tissue (MALT) following exclusive Helicobacter pylori eradication therapy: experience from a large prospective series. Gut 53: 34-37

Greiner A, Marx A, Heesemann J, Leebmann J, Schmausser B, MullerHermelink HK (1994) Idiotype identity in a MALT-type lymphoma and B cells in Helicobacter pylori associated chronic gastritis. Lab Invest 70: $572-578$

Hussell T, Isaacson PG, Crabtree JE, Spencer J (1993) The response of cells from low-grade B-cell gastric lymphomas of mucosa-associated lymphoid tissue to Helicobacter pylori. Lancet 342: 571 - 574

Hussell T, Isaacson PG, Crabtree JE, Spencer J (1996) Helicobacter pylorispecific tumour-infiltrating $\mathrm{T}$ cells provide contact dependent help for development that endocsopic tumour location could be used to derive a prognosis for remission following $H$. pylori eradication.

The disease recurrence rate has been reported to vary from 7 to $12.5 \%$ in patients who once achieved CR (Neubauer et al, 1997; Savio et al, 2000; Stolte et al, 2002; Fischbach et al, 2004). In the update of the multicentre study of Fischbach et al (2004) comprising 90 patients, $4.4 \%$ relapsed after a median follow-up of 44 months. In another Italian series of Savio et al (2000) involving 76 patients, $8 \%$ recurred during a median follow-up of 28 months. Our study showed that MALT lymphoma recurred in $6.0 \%$ of patients with a median follow-up of 41 months. Cumulative recurrence rate was $2.3,7.7$ and $9.3 \%$ at 1,2 and 3 years after CR, respectively. Recurrences were found at 10-22 months after establishment of $\mathrm{CR}$ without the evidence of reinfection or transformation to high-grade lymphoma. Endoscopic appearance, location, depth of invasion and $H$. pylori status were not associated with the recurrence.

At present, it is not known whether any specific characteristic of the patient or of the lymphoma may predispose to a late relapse. With respect to both the rate of recurrence and $H$. pylori reinfection, Neubauer et al (1997) reported only one case of $H$. pylori reinfection among four cases of local recurrence. Fischbach et al (2004) also observed similar results of $H$. pylori reinfection, one patient reinfected among four patients of relapse. Therefore, is $H$. pylori probably not necessary for the lymphomas to relapse after the remission? At the beginning, the low-grade B-cell clone is still dependent on T-cell help (and thus susceptible to eradication therapy), whereas, later in process of clonal evolution, $H$. pylori infection and T-cell help may not be necessary (Hussell et al, 1993, 1996). The relapses may thus indicate that the patients had B-cell lymphomas that had evolved from B-cell clones that were already further progressed when the cure of $H$. pylori infection had been performed. These data suggest that some relapses are a result of the development of a lymphomatous clone that is independent of the $H$. pylori-mediated antigenic drive.

In conclusion, $H$. pylori eradication as single therapy may be appropriate for early-stage gastric MALT lymphoma, which leads to a favourable long-term outcome, offering a real chance of cure. In addition to depth of invasion, our results highlight the relevance of the location of lesions as a predictive factor for tumoural response. Until the clinical and the cellular characteristics of $H$. pylori-dependent and $H$. pylori-independent tumours are better defined, it would be prudent to pursue a cautious approach to tailor the therapeutic strategy and follow-up of these patients. the growth of malignant B cells in low-grade gastric lymphoma of mucosa-associated lymphoid tissue. J Pathol 178: $122-127$

Isaacson PG (1996) Recent developments in our understanding of gastric lymphomas. Am J Surg Pathol 20: S1 -S7

Kahl BS (2003) Update: gastric MALT lymphoma. Curr Opin Oncol 15: $347-352$

Kim JK, Kim WS, Ko YH, Song SY, Oh SY, Kim KH, Nam EM, Jeong HS, Yoon SS, Lee HG, Kang WK, Park CH, Son HJ, Kim JJ (2001) Clinical investigation of gastric MALT lymphoma. Korean J Med 61: 417-424

Montalban C, Santon A, Boixeda D, Redondo C, Alvarez I, Calleja JL, de Argila CM, Bellas C (2001) Treatment of low grade gastric mucosaassociated lymphoid tissue lymphoma in stage I with Helicobacter pylori eradication. Long-term results after sequential histologic and molecular follow-up. Haematologica 86: 609-617

Negrini R, Lisato L, Zanella I, Cavazzini L, Gullini S, Villanacci V, Poiesi C, Albertini A, Ghielmi S (1991) Helicobacter pylori infection induces antibodies cross-reacting with human gastric mucosa. Gastroenterology 101: $437-445$

Neubauer A, Thiede C, Morgner A, Alpen B, Ritter M, Neubauer B, Wundisch T, Ehninger G, Stolte M, Bayerdorffer E (1997) Cure of Helicobacter pylori infection and duration of remission of low-grade 
gastric mucosa-associated lymphoid tissue lymphoma. J Natl Cancer Inst 89: $1350-1355$

Paik KY, Noh JH, Heo JS, Sohn TS, Choi SH, Joh JW, Kim S, Kim YI (2002) Malignant lymphoma of the stomach: a series of eighty-seven cases. J Korea Surg Soc 62: $468-471$

Raderer M, Vorbeck F, Formanek M, Osterreicher C, Valencak J, Penz M, Kornek G, Hamilton G, Dragosics B, Chott A (2000) Importance of extensive staging in patients with mucosa-associated lymphoid tissue (MALT)-type lymphoma. Br J Cancer 83: 454-457

Rohatiner A, d'Amore F, Coiffier B, Crowther D, Gospodarowicz M, Isaacson P, Lister TA, Norton A, Salem P, Shipp M, Ann RS (1994) Report on a workshop convened to discuss the pathological and staging classifications of gastrointestinal tract lymphoma. Ann Oncol 5: 397-400

Ruskone-Fourmestraux A, Lavergne A, Aegerter PH, Megraud F, Palazzo L, de Mascarel A, Molina T, Rambaud JL (2001) Predictive factors for regression of gastric MALT lymphoma after anti-Helicobacter pylori treatment. Gut 48: 297-303

Sackmann M, Morgner A, Rudolph B, Neubauer A, Thiede C, Schulz H, Kraemer W, Boersch G, Rohde P, Seifert E, Stolte M, Bayerdoerffer E (1997) Regression of gastric MALT lymphoma after eradication of Helicobacter pylori is predicted by endosonographic staging. MALT Lymphoma Study Group. Gastroenterology 113: 1087-1090

Savio A, Zamboni G, Capelli P, Negrini R, Santandrea G, Scarpa A, Fuini A, Pasini F, Ambrosetti A, Paterlini A, Buffoli F, Angelini GP, Cesari P, Rolfi F, Graffeo M, Pascarella A, Valli M, Mombello A, Ederle A, Franzin G (2000) Relapse of low-grade gastric MALT lymphoma after Helicobacter pylori eradication: true relapse or persistence? Long-term post-treatment follow-up of a multicenter trial in the north-east of Italy and evaluation of the diagnostic protocol's adequacy. Recent Results Cancer Res 156: $116-124$

Steinbach G, Ford R, Glober G, Sample D, Hagemeister FB, Lynch PM, McLaughlin PW, Rodriguez MA, Romaguera JE, Sarris AH, Younes A, Luthra R, Manning JT, Johnson CM, Lahoti S, Shen Y, Lee JE, Winn RJ, Genta RM, Graham DY, Cabanillas FF (1999) Antibiotic treatment of gastric lymphoma of mucosa-associated lymphoid tissue. An uncontrolled trial. Ann Intern Med 131: 88-95

Stolte M, Bayerdorffer E, Morgner A, Alpen B, Wundisch T, Thiede C, Neubauer A (2002) Helicobacter and gastric MALT lymphoma. Gut 50: iii19-iii24

Watanabe H (1980) Malignant lymphoma of the stomach: a series of eightyseven cases. Stomach Intestine 14: 909-910

Wotherspoon AC (1998) Gastric lymphoma of mucosa-associated lymphoid tissue and Helicobacter pylori. Annu Rev Med 49: $289-299$

Wotherspoon AC, Doglioni C, Diss TC, Pan L, Moschini A, de Boni M, Isaacson PG (1993) Regression of primary low-grade B-cell gastric lymphoma of mucosa-associated lymphoid tissue type after eradication of Helicobacter pylori. Lancet 342: $575-577$

Wundisch T, Thiede C, Morgner A, Dempfle A, Gunther A, Liu H, Ye H, Du MQ, Kim TD, Bayerdorffer E, Stolte M, Neubauer A (2005) Long-term follow-up of gastric MALT lymphoma after Helicobacter pylori eradication. J Clin Oncol 23: 8018-8024 